\title{
"CASADINHO dA QUÍMICA": UMA EXPERIÊNCIA COM O USO DA GAMIFICAÇÃO NO ENSINO DE QUÍMICA ORGÂNICA
}

\author{
“CASADINHO DA QUÍMICA" AN EXPERIENCE USING GAMIFICATION IN \\ ORGANIC CHEMISTRY TEACHING
}

DOI: $\underline{\text { 10.23926/RPD.2526-2149.2020.v5.n3.p1701-1716.id911 }}$

\author{
Alessandra Timóteo \\ Cardoso \\ Licenciada em Química \\ (IFG) \\ Mestranda em Química \\ (UFG) \\ alessandracardoso22k@gmai \\ l.com

\section{Giselle Carvalho \\ Bernardes} \\ Mestre em Psicologia (UFU) \\ Doutoranda em Educação \\ (UFG) \\ Professora no Instituto \\ Federal de Goiás (IFG) \\ giselle.bernardes@ifg.edu.br
}

\section{Lígia Viana Andrade \\ Doutora em Química (UFU) \\ Professora no Instituto \\ Federal de Goiás (IFG) \\ ligia.andrade@ifg.edu.br}

\section{Simone Machado \\ Goulart}

Doutora em Agroquímica

(UFV)

Professora no Instituto

Federal de Goiás (IFG)

simone.goulart@ifg.edu.br

\begin{abstract}
Resumo: Professores e pesquisadores estão sempre em busca de recursos para dinamizar o ensino de Química. A gamificação consiste no uso de elementos de jogos para desenvolver a aprendizagem e pode promover aulas mais dinâmicas e interativas. Nesse contexto, o objetivo desse trabalho foi o desenvolvimento e aplicação de um jogo didático intitulado "Casadinho da Química" visando melhorar a aprendizagem nas aulas de Química Orgânica do terceiro ano do Ensino Médio, em uma escola do município de Itumbiara. A metodologia adotada foi a qualitativa, de caráter experimental, e como instrumento de coleta de dados foram utilizados questionários. Os dados analisados revelam que a utilização do jogo promoveu uma melhora no desenvolvimento dos alunos sobre o conteúdo, além de dinamizar o ensino. Dessa forma, esta pesquisa mostrou que a gamificação é uma metodologia de ensino que pode contribuir com a prática do professor, quando inserida no planejamento de suas aulas.
\end{abstract}

Palavras-chave: Ensino de Química. Jogo didático. Gamificação.

\begin{abstract}
Teachers and researchers have been seeking resources to improve chemistry teaching. Gamification is a methodology in which learning is based on game elements and can help promote more dynamic and interactive classes. In this context, the objective of this work was the development and application of a didactic game intitled "Casadinho da Química" aiming to promote learning in organic chemistry classes, in the third year, from high school in municipal institution of Itumbiara. The methodology used for data analysis was qualitative, experimental, and questionnaires were used. From the analysis of the results, it can be verified that the use of the game promoted an improvement in the development of the students on the content, besides making the teaching more dynamic. Thus, this research showed that gamification is a teaching methodology that can contribute to the teacher's practice, when inserted in the planning of his classes.
\end{abstract}

Keywords: Chemistry Teaching. Teaching Game. Gamification. 


\section{INTRODUÇÃO}

Jogo pode ser definido como atividade ou ocupação voluntária, realizada dentro de certos limites de tempo e de espaço, segundo regras obrigatórias e consentidas entre os participantes, dotado de um fim em si mesmo, acompanhado de um sentimento de tensão e de alegria e uma consciência de ser diferente da vida cotidiana (HUIZINGA, 2007). Em termos simples, o jogo tem regras preestabelecidas e pode ser encarado de forma "não-séria", isto é, associado a uma brincadeira.

Jogos didáticos foram notavelmente investigados a partir do início do século XX devido à expansão de escolas, principalmente na educação infantil. Ocorre que, embora o jogo esteja relacionado ao processo de aprendizagem, ainda é predominante a ideia de que o jogo está mais relacionado à recreação do que aos processos de ensino e de aprendizagem (MIRANDA, 2015). Compreende-se, para fins de análise investigativa, que a ideia de jogo didático pretende aproximar o caráter lúdico existente no jogo à possibilidade de se aprimorar o desenvolvimento cognitivo.

O uso de jogos em atividades de ensino foi objeto de estudo na pesquisa de Souza e colaboradores (2015). Neste estudo, os autores constataram que os jogos têm grande importância para o desenvolvimento da aprendizagem, pois proporcionam uma abordagem interativa nas disciplinas escolares, e "oferece oportunidade para objetivos de descobertas, de forma a desenvolver habilidades de trabalho em equipe, e é proveniente de uma atividade prática a que muitos estudantes estão familiarizados" (SOUZA; REIS; OLIVEIRA, 2015, p. 5).

A gamificação é uma metodologia que tem o objetivo de estimular a ação dos estudantes no ambiente de aprendizagem por meio do uso de jogos. A expressão gamificação origina-se do termo em inglês, "gamification", que se refere ao uso de elementos de jogos em ambientes interativos, com a finalidade de incentivar e motivar as pessoas a atingirem suas metas e objetivos. Por exemplo, a utilização de pontuações, assim como ocorre nos jogos, é uma estratégia bastante utilizada na gamificação, para motivar e incentivar seus jogadores por meio de recompensas (OLIVEIRA, 2018).

De acordo com Leite (2017), os termos "game" e "jogo" podem ser assumidos como similares, uma vez que game é traduzido para o português como jogo e significa uma ação com regras, diferente da palavra play, que também pode ser traduzida como jogo, mas no sentido de diversão, prazer, lúdico, não necessariamente submetido a regras. Contudo, o número de publicações com estudos científicos sobre gamificação no ensino da Química é limitado (LEITE, 2017), envolvendo a gamificação em aulas de Química. 
Assim, essa pesquisa tem como objetivo a confecção e aplicação de um jogo didático utilizado como um processo de gamificação, visando promover a aprendizagem nas aulas de Química Orgânica do terceiro ano do ensino médio integrado com curso técnico em Química do IFG (Instituto Federal de Goiás) campus Itumbiara. A escolha da disciplina Química Orgânica justifica-se por requerer compreensão de conteúdos presentes no cotidiano, mas que são dificilmente visualizados sem a mediação de instrumentos. Posteriormente, visando enriquecer a literatura acerca da utilização de jogos no ensino de Química, analisa-se as vantagens da utilização desse recurso no processo de ensino aprendizagem.

\section{REFERENCIAL TEÓRICO}

\subsection{JOGOS DIDÁTICOS NO ENSINO DA QUÍMICA}

Jogos e brincadeiras estão inseridos no cotidiano das pessoas desde muito cedo e se perpetuam por toda a vida. Ainda que por diversão, o ato de brincar está associado a algum aprendizado, tal como agilidade, raciocínio lógico, coordenação motora, porém, é comum as pessoas não perceberem que estão desenvolvendo tais habilidades. Soares (2015) afirma que, quando se brinca, muitas vezes não há consciência de que está havendo a assimilação de algum conhecimento, ou a absorção de outros subsídios ao desenvolvimento intelectual, brinca-se porque é prazeroso.

Para Vygotsky (1989), o brincar é fundamental para o desenvolvimento cognitivo e intelectual, nesse sentido, o jogo atua na zona de desenvolvimento proximal (ou iminente) do estudante. Ou seja, o jogo é um instrumento que media a relação entre o sujeito e objeto de conhecimento, possibilitando o avanço da aprendizagem de um conteúdo já consolidado para a potencialidade de aprender um novo conteúdo.

Assim, o jogo pode percorrer o caminho necessário para que o indivíduo venha a desenvolver funções que estão amadurecendo (iminentes), e que serão consolidadas, estabelecendo-se em nível de desenvolvimento real, onde se considera o que o indivíduo já tem conhecimento.

O uso de jogos com fins educacionais é uma ferramenta didática que auxilia no desenvolvimento de uma aula mais dinâmica e rompe com o ensino tradicional (ANDRADE et al., 2017). Na grande área do conhecimento Ciências da Natureza, especificamente no ensino de Química, na abordagem tradicional, aquela em que o professor expõe o conteúdo a partir do livro didático, sem a participação ativa do estudante no processo de ensino e de aprendizagem, 
o conteúdo é apresentado pronto, e cabe ao aluno a posição de receptor que apenas copia e resolve exercícios de forma mecânica. Ou seja, nessa abordagem, prevalece a transmissão e reprodução de conteúdo, e não o sentido da educação como constituição do conhecimento pelo próprio indivíduo (MIZUKAMI, 1986).

Estudos afirmam que os professores podem utilizar jogos didáticos como recursos auxiliares nos processos de ensino e aprendizagem em qualquer área de ensino. Sendo assim, é importante expandir a investigação científica e o desenvolvimento de jogos voltados para a área da Química (CUNHA, 2012; SOARES, 2015).

Acredita-se que com a evolução tecnológica, em que os meios de comunicação estão em constante desenvolvimento, o professor possa aproveitar o uso das tecnologias para estimular a posição ativa e reflexiva do aluno em sala de aula. É justamente por esse motivo que os jogos se apresentam como uma alternativa simples e eficaz, pois além de usarem materiais alternativos e de fácil aquisição para sua confecção, sua utilização propõe motivar os estudantes para o estudo da Química, afastando-os de uma postura passiva em sala de aula (SOARES, 2015).

O uso de jogos em sala de aula também propicia, de forma espontânea e divertida, momentos de interação entre professor-aluno e aluno-aluno. Essa interação é extremamente importante pois promove o desenvolvimento social dos indivíduos, por meio da qualidade dos relacionamentos.

Os jogos ajudam o estudante a elaborar novas formas de pensamento, desenvolvendo e enriquecendo sua coordenação motora, raciocínio lógico, criatividade e personalidade. Já o professor, quando utiliza o jogo em sala de aula, ocupa uma posição de condutor, estimulador e avaliador da aprendizagem dos alunos (CUNHA, 2012).

Em um estudo sobre as relações entre o jogo e a educação, Kishimoto (1996) afirma que o jogo educativo merece algumas considerações quanto às suas funções lúdica e educativa. A função lúdica propicia diversão, e a educativa tem o objetivo de ensinar conceitos aos alunos ou completar seus conhecimentos sobre determinado assunto. Sendo assim, o equilíbrio entre essas duas funções deve ser parte dos objetivos no jogo.

\subsection{A GAMIFICAÇÃO COMO METODOLOGIA DE ENSINO}

Levando-se em consideração o conceito de jogos didáticos e sua importância no processo de aprendizagem, faz-se necessário definir o conceito de gamificação como metodologia de ensino. Estudos apontam que a gamificação refere-se à utilização de elementos 
de jogos para suscitar motivação e envolvimento na resolução de um desafio, de caráter cognitivo, no contexto educacional. Nessa perspectiva, enquanto os jogos didáticos se referem a recursos pedagógicos, a gamificação remete-se a uma Metodologia Ativa de ensino que visa promover a aprendizagem baseada em games, isto é, relacionar a ação de aprender aos elementos dos jogos (FARDO, 2011; COSTA; VERDAUX, 2016).

Esses elementos podem ser desde objetivos, regras, feedback imediato, premiação, dinamismo, competição, cooperação, até a possibilidade de acertos e erros no processo de aprendizagem. Apesar da gamificação utilizar vários elementos presentes nos jogos, a principal diferença entre eles, é a ausência da jogabilidade - ou seja, a capacidade que um jogo tem de ser facilmente completado. Dessa forma, a gamificação pode apresentar além da diversão, elementos cognitivos fundamentais, tanto para a construção bem como para a organização do aprendizado (LEITE, 2017; SILVA, SALES, CASTRO, 2019).

No ensino de Química alguns autores já utilizaram a gamificação como metodologia de ensino, como no trabalho de Castro e Fernandes (2013a), que propuseram um jogo sobre reações básicas da Química Orgânica, tendo como foco alunos calouros das universidades. Os mesmos autores desenvolveram um ambiente virtual de ensino de Química Orgânica baseado em gamificação. Este ambiente continha opções de vídeo, imagens e jogos, em que os estudantes podem acessar conteúdos de apoio ao aprendizado e sejam estimulados a cumprir as tarefas (FERNANDES; CASTRO, 2013b).

O jogo didático pode servir para auxiliar no processo de gamificação em um determinado conteúdo, pois promove habilidades como a participação, o engajamento, além de uma melhora na motivação e nos aspectos cognitivos dos estudantes acerca da compreensão do conteúdo abordado. Outro propósito de se utilizar a gamificação em sala de aula é a socialização, estabelecendo respeito e diálogo na turma (SILVA; SALES; CASTRO, 2019).

\section{Metodologia}

Para a realização dessa pesquisa foi utilizada a metodologia qualitativa de caráter experimental. Segantini (2013) relata que as pesquisas desenvolvidas no campo da metodologia qualitativa possibilitam o entendimento das particularidades do comportamento dos indivíduos. Esta compreensão sobre o comportamento contribui no processo de mudança de um grupo, classifica e compreende processos vividos por grupos sociais e analisa a interação de certas variáveis. 
A pesquisa se desenvolveu em três etapas: aplicação de questionário inicial, construção e aplicação do jogo e aplicação do questionário final. Os questionários foram usados na coleta de dados por serem um instrumento de pesquisa eficiente, que permite a obtenção de dados mais rápidos e precisos, maior liberdade nas respostas e atinge maior número de pessoas, simultaneamente (LAKATOS; MARCONI, 2003).

O questionário inicial, anterior à aplicação do jogo, foi elaborado com a finalidade de identificar as principais dificuldades dos estudantes em relação ao conteúdo de Química Orgânica, e então construir as cartas de cada jogo. Já o questionário posterior, visava verificar se houve progresso dos estudantes em relação à aprendizagem do conteúdo e se o jogo auxiliou nesse processo. Além do mais, também buscava coletar a avaliação e sugestões dos alunos quanto ao uso do jogo como recurso didático em aulas de Química.

\subsection{CaSadinho da Química e suas Regras}

O Casadinho da Química é um jogo de tabuleiro que contém 28 casas e que tem início e fim. O tabuleiro foi construído com tecido Não Tecido (TNT) e papel cartão, com um conjunto de dois dados (Figura 1): um contém seis cores (vermelho, verde, amarelo, roxo, laranja e branco); o outro dado é constituído por números de um a seis, que representam a quantidade de casas que o grupo irá andar caso acerte as perguntas propostas, dando origem ao título, “Casadinho da Química”.

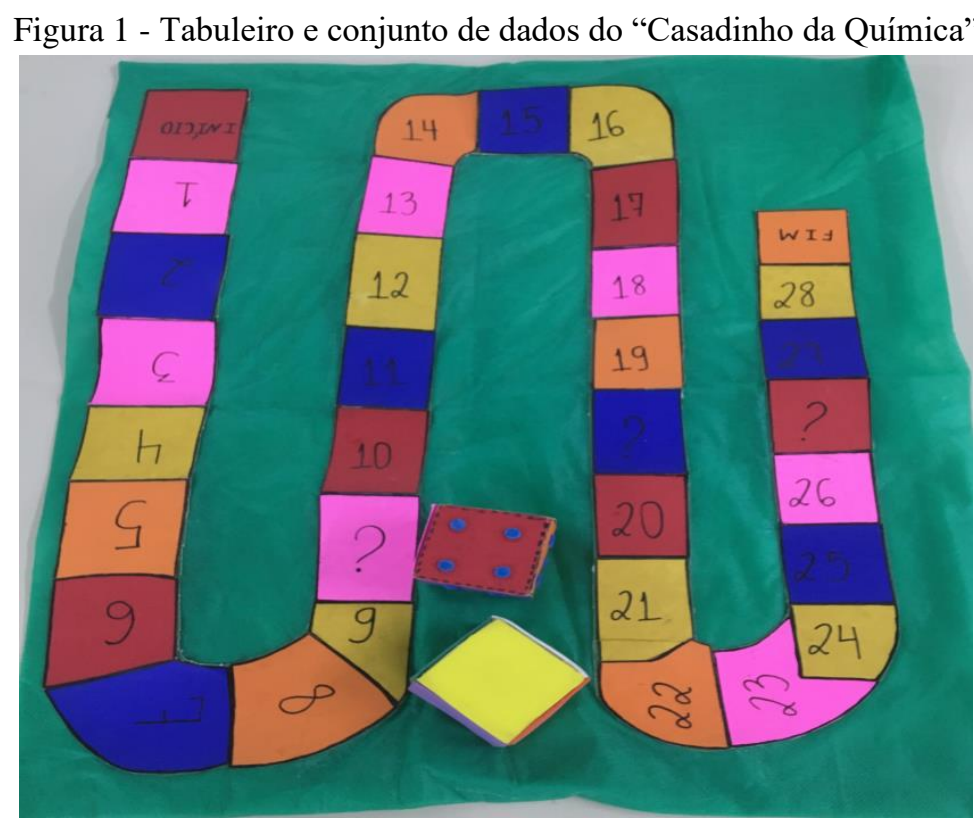

Fonte: Criado pelo Autor. 
As cartas numeradas de um a oito contêm o conteúdo da disciplina de Química Orgânica - funções orgânicas, distribuído em cinco envelopes, cada um referente a uma face do dado. Segundo Teixeira e Apresentação (2014), o primeiro ponto a ser analisado pelo professor que pretende utilizar-se de algum jogo em sala de aula é avaliar o objetivo que se quer atingir com a sua utilização. Identificar previamente o objetivo permite direcionar e atribuir significado para a atividade com o jogo, estabelecendo eventuais conexões com outras áreas de conhecimento.

As questões foram elaboradas a partir do conteúdo estudado em sala de aula, bem como nas dificuldades apresentadas pelos estudantes no primeiro questionário. Haviam cartas com perguntas sobre montagem da fórmula de compostos, classificação dos átomos de carbono em uma cadeia, classificação das cadeias carbônicas, contagem de carbonos, nomenclatura, tipos de funções orgânicas e produtos usados no cotidiano que contém essas funções. Ao todo, foram elaboradas 40 questões, distribuídas em 5 envelopes com 8 questões cada (Figura 2).

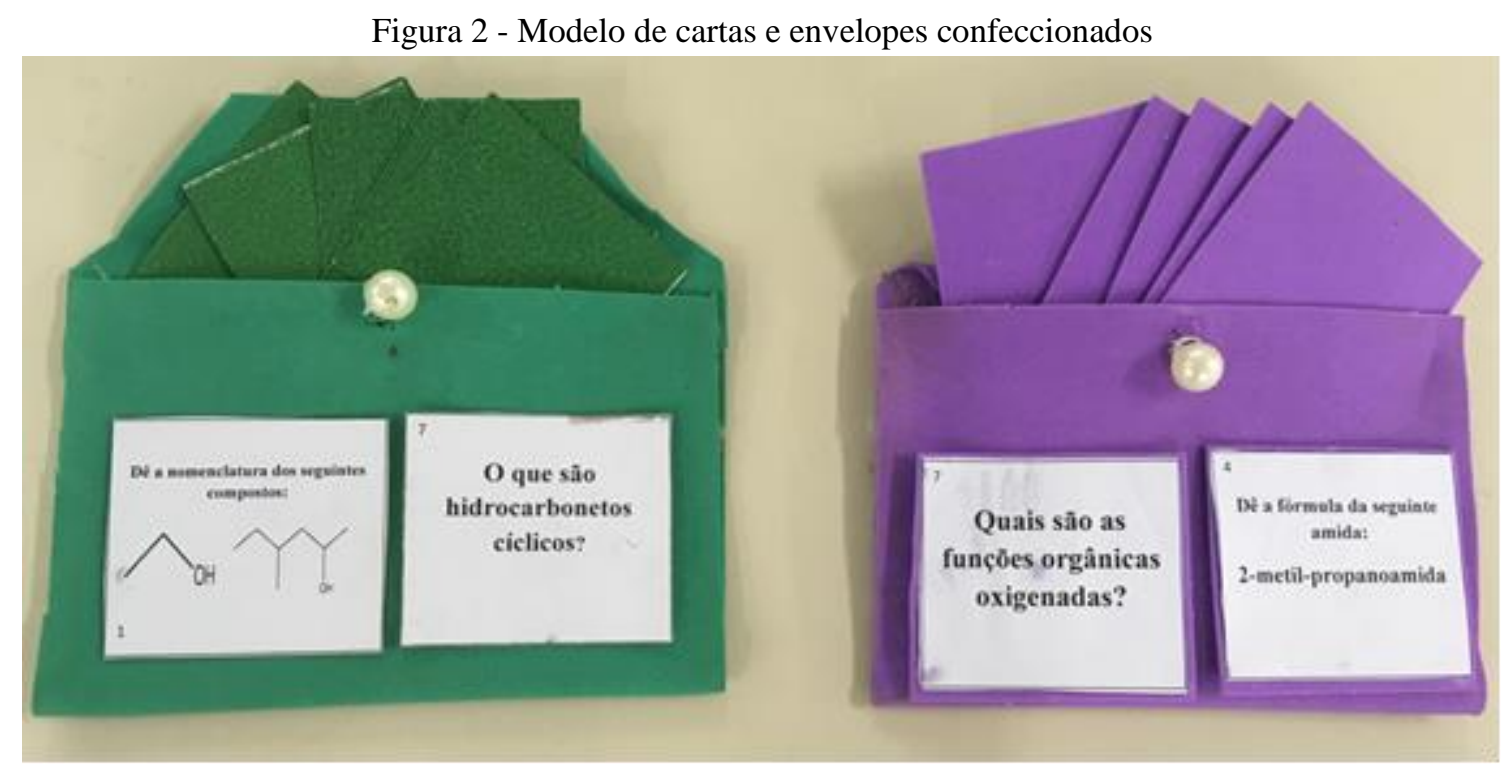

Fonte: Criado pelo Autor.

A forma de jogar é bem simples: os alunos são distribuídos em grupos e usam peões feitos de papel cartão de cores diferentes para marcar as casas, cada peão representa um grupo. Um aluno então, joga os dois dados e responde à carta dentro do envelope, da cor que sair. Exemplo: o aluno jogou os dados e um caiu na cor laranja, e no outro caiu no número seis. Então, ele pega uma carta do envelope de cor laranja e como auxílio do grupo tem três minutos para discutir sobre a questão e chegar à resposta considerada certa. Caso o grupo acerte, anda a quantidade de casas que saiu no dado, conforme o exemplo, andariam seis casas. Caso erre, não anda e a carta volta para o envelope. 
Conforme o grupo vai acertando as questões e de acordo com o número que sair no dado, os peões vão andando no tabuleiro. Se o dado de cores cair na cor branca, o grupo deverá passar a vez para o próximo jogar. Ainda no tabuleiro, foram inseridas algumas questõessurpresa, como: "passe a vez", "perdeu um ponto", caso o peão pare em uma das casas com interrogação, a fim de promover uma descontração entre os grupos (Figura 3). O grupo que chegar primeiro ao fim do tabuleiro ganha o jogo.

Figura 3 - Cartas-surpresa do "Casadinho da Química"

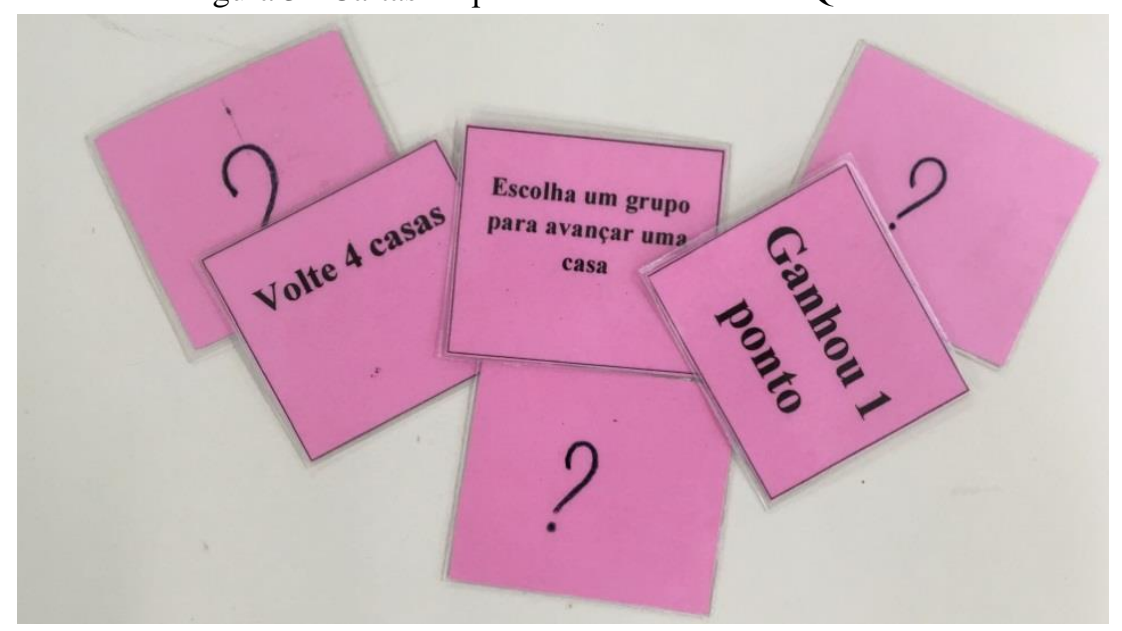

Fonte: Criado pelo Autor.

O Casadinho da Química foi aplicado para 25 alunos do $3^{\circ}$ ano do ensino médio Integrado com curso técnico em Química do IFG - campus Itumbiara, nas aulas de Química Orgânica. Antes da aplicação, os estudantes responderam ao primeiro questionário que continha cinco questões específicas do conteúdo e cinco questões sobre o uso de recursos didáticos nas aulas de Química.

Os alunos foram distribuídos em cinco grupos de cinco pessoas, e cada grupo escolheu uma cor de peão para lhes representar no tabuleiro (Figura 4). Por fim, os grupos vencedores $\left(1^{\circ}\right.$ e $2^{\circ}$ lugar) ganharam um saco de pirulitos (premiação simbólica) para motivar o aprendizado dos estudantes, alinhando a função educativa com a função lúdica do jogo, incentivando a participação dos estudantes na atividade. A premiação também é um elemento da gamificação, pois como um elemento de jogo, medalhas e troféus, representam socialmente uma vitória. 
Figura 4 - Alunos discutindo as questões do jogo com o grupo

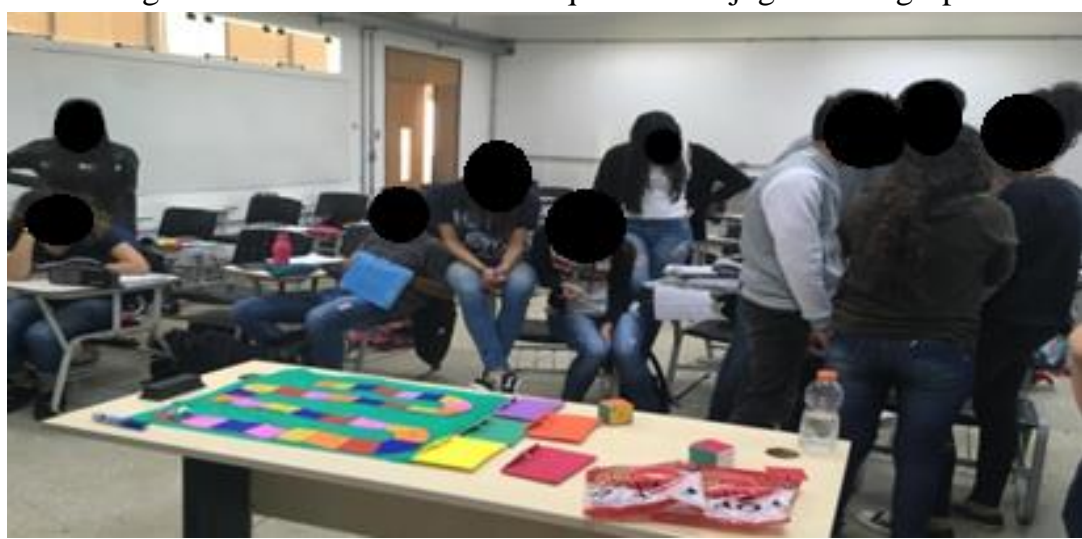

Fonte: Criado pelo Autor.

Duas semanas após a realização do jogo "Casadinho da Química", foi aplicado outro questionário para verificar se a atividade contribuiu para o desenvolvimento dos estudantes acerca do conteúdo apresentado. Esse questionário continha perguntas dissertativas e objetivas sobre Química Orgânica e questões para que os alunos sugerissem e relatassem sobre a experiência com o jogo "Casadinho da Química".

\section{Discussão Resultados}

A Tabela 1 mostra o resultado de algumas perguntas selecionadas no primeiro questionário, aplicado para o $3^{\circ}$ ano do ensino médio.

Tabela 1 - Resultados da parte específica do tema e opinião dos alunos acerca do conteúdo funções orgânicas

\begin{tabular}{|c|c|c|c|c|}
\hline Questão & \multicolumn{4}{|c|}{ Resposta } \\
\hline \multirow{2}{*}{$\begin{array}{l}\text { 1. Qual a sua opinião } \\
\text { sobre o conteúdo de } \\
\text { funções orgânicas? }\end{array}$} & Complexo & Necessário & Interessante & - \\
\hline & $28 \%$ & $16 \%$ & $56 \%$ & - \\
\hline \multirow[t]{2}{*}{$\begin{array}{l}\text { 2. Em que parte do } \\
\text { conteúdo você tem } \\
\text { mais dificuldade? }\end{array}$} & $\begin{array}{l}\text { Nomenclatura } \\
\text { dos compostos }\end{array}$ & $\begin{array}{c}\text { Diferenciar as } \\
\text { funções orgânicas }\end{array}$ & $\begin{array}{l}\text { Nomenclatura das } \\
\text { funções orgânicas }\end{array}$ & $\begin{array}{c}\text { Identificação } \\
\text { de funções } \\
\text { orgânicas }\end{array}$ \\
\hline & $32 \%$ & $16 \%$ & $16 \%$ & $36 \%$ \\
\hline \multirow{2}{*}{$\begin{array}{l}\text { 3. O composto } \\
\text { propanoato de metila } \\
\text { pertence a qual } \\
\text { função orgânica? }\end{array}$} & Acertos & Erros & - & - \\
\hline & $69,3 \%$ & $30,7 \%$ & - & - \\
\hline \multirow{2}{*}{$\begin{array}{l}\text { 4. O que são ligações } \\
\text { simples, dupla e } \\
\text { tripla? }\end{array}$} & Acertos & Erros & Acertos Parciais & $\begin{array}{c}\text { Não } \\
\text { responderam }\end{array}$ \\
\hline & $24 \%$ & $24 \%$ & $32 \%$ & $20 \%$ \\
\hline
\end{tabular}

Fonte: Os autores (2020). 
Os dados da Tabela 1 mostram que na primeira questão os alunos consideraram o tema funções orgânicas interessante em sua maioria (56\%). Porém, há um percentual de alunos (28\%) que ainda alegam ser um tema complexo, de difícil entendimento. Quando perguntados sobre o tópico de mais dificuldade, a maior parte (36\%) dos estudantes alegou que era a identificação de funções orgânicas em um grupo funcional.

As orientações curriculares nacionais sugerem que, para o tema funções orgânicas, é necessário que os alunos conheçam e identifiquem as estruturas químicas dos hidrocarbonetos, álcoois, aldeídos, cetonas, ácidos carboxílicos, ésteres, carboidratos, lipídeos e proteínas e que façam a associação entre a nomenclatura de substâncias com a organização de seus constituintes (OLIVEIRA et al., 2012).

$\mathrm{Na}$ terceira questão nota-se que apesar de afirmarem ter dificuldade de associar a função orgânica como grupo funcional, a maioria dos estudantes, 69 \%, soube responder corretamente a questão. Já na quarta questão, pode-se notar que os estudantes ainda apresentavam dúvidas sobre o conceito do número de ligações que os carbonos fazem em uma estrutura, apresentando parte da definição. Fazendo uma análise dos resultados, houve a possibilidade de utilizar o jogo com a função de revisão de conceitos apresentados pelo professor, pois os alunos precisavam organizar e consolidar o conhecimento, de desenvolvimento cognitivo e intelectualmente e posteriormete avançar para o próximo conteúdo, conforme Vygotsky (1989).

O uso do jogo como atividade de revisão permitiu a articulação entre as funções lúdica e educativa (KISHIMOTO, 1996) do jogo "Casadinho da Química”, pois além de propiciar um momento de socialização e descontração, também foi possível revisitar conceitos de Química Orgânica que os alunos ainda tinham dúvidas e completar os processos de ensino e de aprendizagem, contribuindo para o desenvolvimento dos estudantes.

De acordo com Cunha (2012), um dos motivos que justifica o uso do jogo no planejamento de um professor é a revisão de pontos ou conceitos importantes do conteúdo estudado, assim como a promoção da contextualização do conhecimento. Nessa vertente, construíram-se as cartas do jogo, com questões embasadas nos resultados da questão dois do questionário, que tratava do conteúdo com maiores dificuldades, e a partir dessa construção, o jogo foi aplicado com a turma.

Tanto no momento de construção, bem como no momento de execução da atividade, houve um cuidado especial a cada um dos elementos que formam este jogo, para que o “Casadinho da Química” fosse utilizado como um recurso no processo de gamificação. Dessa 
forma, os elementos trabalhados foram: objetivos do jogo, as regras estabelecidas, o feedback imediato aos estudantes, e, na aceitação dos estudantes frente ao jogo estabelecido.

A Tabela 2 apresenta algumas questões feitas no questionário posterior à aplicação do jogo. Essas questões faziam referência tanto a parte específica do conteúdo, bem como a utilização do jogo.

Tabela 2 - Resultados do questionário posterior aplicado aos alunos acerca do "Casadinho da Química"

\begin{tabular}{|c|c|c|c|c|}
\hline Questão & \multicolumn{4}{|c|}{ Resposta } \\
\hline \multirow[b]{2}{*}{$\begin{array}{l}\text { 1. Na sua opinião, } \\
\text { o uso do jogo } \\
\text { auxiliou na } \\
\text { aprendizagem } \\
\text { sobre o conteúdo } \\
\text { de Química } \\
\text { Orgânica? }\end{array}$} & Sim & Não & - & - \\
\hline & 92,3 & 7,7 & - & - \\
\hline \multirow{2}{*}{$\begin{array}{c}\text { 2. O que você mais } \\
\text { gostou no jogo? }\end{array}$} & Conteúdo & Estética & $\begin{array}{l}\text { Divisão de } \\
\text { grupos }\end{array}$ & $\begin{array}{l}\text { Tempo para } \\
\text { resposta }\end{array}$ \\
\hline & 76,9 & 11,5 & 7,7 & 3,8 \\
\hline \multirow{2}{*}{$\begin{array}{l}\text { 3. Qual função } \\
\text { pertence ao grupo } \\
\text { funcional: C-O-C } \\
\text { (oxigênio entre } \\
\text { carbonos) }\end{array}$} & Acertos & Erros & - & - \\
\hline & $88 \%$ & $12 \%$ & - & - \\
\hline \multirow{2}{*}{$\begin{array}{c}\text { 4. Os } \\
\text { hidrocarbonetos } \\
\text { são divididos em } \\
\text { três grupos de } \\
\text { acordo com o tipo } \\
\text { de ligação. Quais } \\
\text { são esses grupos? }\end{array}$} & Acertos & Erros & Acertos Parciais & $\begin{array}{c}\text { Não } \\
\text { responderam }\end{array}$ \\
\hline & $65,5 \%$ & $11,5 \%$ & $3,8 \%$ & $19,2 \%$ \\
\hline
\end{tabular}

Fonte: Os autores (2020).

A primeira questão referia-se à utilização do jogo como recurso didático para revisão dos conteúdos. Pode-se constatar que a maioria dos estudantes $(92,3 \%)$, alegou que o jogo auxiliou no processo de ensino aprendizagem e construção de conhecimento. Isso é comprovado na segunda questão, quando foram interrogados sobre o que mais gostaram no jogo, e responderam que foi o conteúdo das cartas. Segundo os alunos as cartas tinham uma linguagem de fácil compreensão e eram coerentes com o conteúdo estudado em sala de aula.

Ainda nessa questão, foi pedido para que relatassem o que mais chamou a atenção deles no jogo, e dentre as respostas, descreveram: a criatividade, a variedade das perguntas, a 
interatividade entre os grupos, a divisão de cores por tema, a dinâmica do jogo, entre outras características que contribuíram para a diversão e o aprendizado da turma.

Uma das características mencionadas foi a dinâmica do jogo. Entende-se por dinâmica a organização das regras e forma com que ocorreu a participação dos alunos diretamente na atividade, o que contribuiu para a construção do conhecimento. Segundo Silva Sales e Castro (2019), um dos elementos importantes no processo de gamificação, e que devem estar conectados com os demais, são as regras. Elas delimitam espaços em que o jogador (aluno ou grupo) pode explorar, e isso faz com que ele desenvolva o raciocínio estratégico.

Além disso, durante a execução do jogo, percebeu-se que os alunos tiveram grande interação entre eles, tanto na discussão das cartas quanto no rodízio dos integrantes do grupo, para jogar o dado e pegar as perguntas. Silva Loja e Pires (2020) afirmam que um dos benefícios que a utilização de elemento de jogos apresenta, é o desenvolvimento das relações interpessoais, como o trabalho em equipe e comprometimento com a atividade.

Outro ponto que chamou a atenção foi a competição entre os grupos. Durante a execução do jogo, os alunos ficaram tão empolgados para ver quem iria chegar primeiro ao final do tabuleiro que torciam para que o dado caísse na cor branca quando os grupos adversários jogavam. Isso significava que o grupo teria que passar a vez para o próximo jogar. Outro aspecto interessante foi que, ao errar uma questão, o grupo deveria devolver a questão para o envelope para ser pega por outros grupos em outra rodada, dependendo do sorteio até que alguém a acertasse. Então, quando algum grupo errava, os outros já tentavam decifrar a resposta para que, caso pegasse a carta, já teriam a resposta pronta.

Segundo Soares (2015), nesse tipo de atividade, as regras desempenham um papel importante, pois caso se queira atingir a aprendizagem de alguns conceitos, passa-se primeiramente por regras a serem obedecidas, para que o jogo funcione a contento e se atinjam os objetivos propostos. De acordo com Leite (2017), alguns pontos que permitem o uso da gamificação na educação são: a motivação dos alunos a aprenderem os conteúdos disciplinares e a influência sobre o comportamento do aluno em sala de aula. Notou-se que, com o uso da premiação simbólica, dois sacos de pirulitos para o primeiro e segundo lugar, os alunos ficaram empolgados em ganhar o jogo, participando mais ativamente dessa aula.

Nas questões três e quatro do questionário, pode-se observar que após a utilização do jogo, a maioria dos alunos conseguiu associar a função orgânica ao grupo funcional e relatar algumas características dos grupos específicos. É possível associar este fato à mediação dos pesquisadores na resolução de dúvidas durante todo o período de execução do jogo, o que foi 
de grande relevância para promover o ensino do conteúdo, pois quando os grupos chegavam à resposta certa, era discutido com o restante da tuma o conceito de determinada questão. Isso pode ser associado a outro elemento relevante da gamificação: o feedback imediato aos alunos. Este elemento serviu para os alunos terem uma noção de até onde seu conhecimento sobre o conteúdo estava consolidado e quais pontos eles ainda precisavam compreender. Além disso, como Silva, Sales e Castro (2019) apontam, essa ação fomenta a motivação dos alunos.

Nas questões específicas, os alunos demonstraram um desenvolvimento considerável, mostrando que o objetivo de revisão dos conteúdos de Química Orgânica no jogo foi atingido. Além da questão específica dos conteúdos, foram observadas habilidades sociais em processo, como a interatividade entre os grupos, a tomada de decisão, o trabalho em equipe, a dinâmica e o respeito às regras do jogo, a cooperação entre os membros do grupo, além de promover a aceitação e o respeito pela fala do colega, no que se refere à discussão de respostas.

Investigações científicas na área da Educação confirmam que atividades com jogos ajudam no aprendizado, além de oferecer diversão e entretenimento. Ao professor que planeja a atividade educativa, cabe adaptar o conteúdo programático à proposta do jogo (CARDOSO; ANDRADE; SANTANA, 2019).

No que se refere ao uso da gamificação em sala de aula, é importante pensar o objetivo que se deseja atingir, desde o planejamento e a confecção de cada peça (no caso dos jogos), o estabelecimento de regras, o levantamento bibliográfico, até a análise dos dados anteriores e posteriores à aplicação dos jogos, para se fazer um diagnóstico educacional do que foi alcançado com o uso da metodologia escolhida.

\section{CONSIDERAÇões Finais}

A dinamização do ensino de Ciências e Matemática tem sido alvo de pesquisas nos últimos anos. Alinhada a essa proposta, a presente investigação buscou desenvolver e utilizar um jogo didático, de modo a promover a aprendizagem por meio da gamificação em uma turma do ensino médio integrado com curso técnico em Química do IFG, campus Itumbiara.

Essa pesquisa mostrou que a gamificação além de ser uma metodologia ativa, complementa as aulas expositivas e provoca engajamento dos alunos para vencer as etapas propostas pelo recurso didático. Entretanto, é importante lembrar que, para que o uso dessa metodologia seja eficiente, é preciso que haja planejamento da atividade, clareza na explicação do conteúdo e resolução de dúvidas, se possível, coleta de dados para elaboração de um diagnóstico educacional da turma e análise do perfil dos alunos para a construção das cartas. 
Constatou-se que, durante a interação dos alunos na aplicação do jogo, houve um desenvolvimento não apenas no processo de aprendizagem dos estudantes e no interesse pelo conteúdo estudado, mas também observou-se que o jogo permitiu o desenvolvimento de habilidades socioemocionais dos estudantes, como a relação aluno-aluno, relação professoraluno, cooperação, criatividade, entre outras.

Os resultados do questionário final indicaram um crescimento no percentual de acertos, revelando maior organização do conhecimento dos alunos sobre Química Orgânica após a utilização do "Casadinho da Química". Conclui-se que o jogo didático relacionado com o conteúdo, por meio da gamificação, como metodologia, gerou resultados significativos na aprendizagem dos alunos, demonstrando ser uma ferramenta didática, eficaz e versátil no ensino de Química.

\section{Agradecimentos}

Ao Instituto Federal de Goiás - campus Itumbiara, ao Núcleo de Pesquisa em Processos Educacionais (NuPEPE), ao Núcleo de Pesquisa e Estudos em Química de Goiás (NUPEQUI), e ao Programa de Educação Tutorial do curso de Licenciatura em Química (PET-Química).

\section{REFERÊNCIAS}

ABRAÃO, Juliano dos Santos; SOUSA, Flaviane; CARLOS, Elenise; BRESCI, Melissa. In:

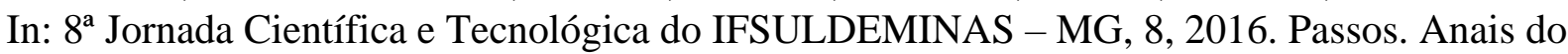
Instituto Federal do Sul de Minas Gerais, Passos: IFSULDEMINAS, 2016. p. 1-4. Disponível em: https://jornada.ifsuldeminas.edu.br/index.php/jcpas/jspas/paper/viewFile/2415/1818. Acesso em 19 agosto 2020.

ANDRADE, Whystney Houston Novais de; JESUS, Weslei Oliveira de; FAVORITO, Ana Paula Machado; MOREIRA, Débora Astoni. Estratégias para o ensino de Química com jogos lúdicos. In: FALEIRO, Wender. ASSIS, Maria Paulina de. Ciências da natureza e formação de professores. Jundiaí: Paco, 2017. p. 303-308.

CARDOSO, Alessandra Timóteo; ANDRADE, Lígia Viana; SANTANA, Vanessa Campos. In. II Congresso Nacional de Ensino de Ciências e Formação de Professores, 2, 2019, Catalão. Anais do II CECIFOP, Catalão: UFG, 2019. p. 1635-1646. Dísponível em: http://cecifop.sistemasph.com.br/index.php/cecifop/CECIFOP2019/schedConf/presentations. Acesso em: 19 agosto 2020.

CASTRO, Fernando dos Santos; FERNANDES, Anita Maria da Rocha. In: Computer on the Beach 2013, 4, 2013, Florianópolis. Anais - Resumos Expandidos. Florianópolis: UNIVALI. 2013a. p. 328-330. Disponível em: file:///C:/Users/ccard/Downloads/6238-16860-1-SM.pdf. Acesso em 30 agosto 2020.

COSTA, Tiago Machado da; VERDEAUX, Maria de Fátima da Silva. Gamificação de materiais didáticos: uma proposta para a aprendizagem significativa da modelagem de 
problemas físicos. Experiências em Ensino de Ciências, v.11, n. 2, p. 60-105, 2016. Disponível em: https://if.ufmt.br/eenci/artigos/Artigo_ID311/v11_n2_a2016.pdf. Acesso em: 30 ago. 2020.

CUNHA, Márcia Borin da. Jogos no Ensino de Química: Considerações Teóricas para sua Utilização em Sala de Aula. Química Nova na Escola, v. 34, n. 2, p. 92-98, 2012. Disponível em: http://qnesc.sbq.org.br/online/qnesc34_2/07-PE-53-11.pdf. Acesso em 30 ago. 2020.

FARDO, Marcelo Luis. A gamificação aplicada em ambientes de aprendizagem. Novas Tecnologias na Educação, v. 11, n. 1, p. 1-8, 2013. Disponível em: https://seer.ufrgs.br/renote/article/view/41629/26409. Acesso em: 30 ago. 2020.

FERNANDES, Anita Maria da Rocha; CASTRO, Fernando dos Santos. In. XXIV Simpósio Brasileiro de Informática na Educação, 24, 2013, Campinas. Anais do XXIV Simpósio Brasileiro de Informática na Educação (SBIE 2013). Campinas 2013b. p. 124-133. Disponível em: https://www.br-ie.org/pub/index.php/sbie/article/view/2490. Acesso em 30 agosto 2020.

HUIZINGA, Johan. Homo ludens: O jogo como elemento da Cultura. São Paulo: Perspectiva, 2007.

KISHIMOTO, Tizuko Morchida. Jogo, Brinquedo, Brincadeira e a Educação. São Paulo: Cortez, 1996.

LAKATOS, Eva Maria; MARCONI, Marina de Andrade. Fundamentos de metodologia científica. São Paulo: Atlas, 2003.

LEITE, Bruno Silva. Gamificando as aulas de Química: uma análise prospectiva das propostas de licenciandos em Química. Novas Tecnologias na Educação. v. 15, n. 2. P. 1-10, 2017. Disponível em: https://seer.ufrgs.br/renote/article/view/79259/46153. Acesso em 30 ago. 2020.

MIRANDA, Ana Flávia Souza. Jogos Pedagógicos no Processo de Ensino e Aprendizagem em Química na Modalidade Educação de Jovens e Adultos. Dissertação (Mestrado em Educação em Ciências e Matemática). Universidade Federal de Goiás, Goiânia, 2015. Disponível em: http://repositorio.bc.ufg.br/tede/bitstream/tede/4924/5/Disserta\%C3\%A7\%C3\%A30\%20\%20Ana\%20Fl\%C3\%A1via\%20Souza\%20Miranda\%20-\%202015.pdf. Acesso em 20 ago. 2020.

MIZUKAMI. Maria da Graça Nicoletti. Ensino, as abordagens do processo. São Paulo: EPU, 1986.

OLIVEIRA, Ana Paula Sabino; MACÊDO, Aline Pereira; TEIXEIRA JÚNIOR, José G. In. XVI Encontro Nacional de Ensino de Química (XVI ENEQ) e X Encontro de Educação Química da Bahia (X EDUQUI), 16, 10, 2012. Salvador. Anais do XVI ENEQ/X EDUQUI, Salvador, 2012. p. 1-10. Disponível em:

https://portalseer.ufba.br/index.php/anaiseneq2012/article/view/7897/5196. Acesso em 10 agosto 2020. 
OLIVEIRA, Renato de Araújo. Uma ferramenta de gamificação para avaliação de aprendizagem de disciplinas de graduação em computação. 2018. 94f. São Luís: Dissertação (Programa de Pós-Graduação em Ciência da Computação da UFMA) Universidade Federal do Maranhão, São Luís, 2014, Disponível em: https://tedebc.ufma.br/jspui/bitstream/tede/2324/2/Renato\%20de\%20Ara\%C3\%BAjo\%20Oli veira.pdf. Acesso em 10 ago. 2020.

SEGANTINI, Paulo Henrique. Os jogos lúdicos no processo de ensino-aprendizagem da matemática. 2013. 43f. Medianeira: Monografia (Pós-graduação em Educação: Métodos e Técnicas de Ensino). Universidade Tecnológica Federal do Paraná, Medianeira, 2013 Disponível: http://repositorio.roca.utfpr.edu.br/jspui/bitstream/1/4432/1/MD_EDUMTE_2014_2_72.pdf. Acesso em 20 de ago. 2020.

SILVA, Ezequiel Santos; LOJA, Luiz Fernando Batista; PIRES, Diego Arantes Teixeira. Quiz Molecular: Aplicativo Lúdico Didático Para o Ensino de Química Orgânica. Revista Prática Docente, v. 5, n. 1, p. 172-192, jan/abr 2020. Disponível em: http://periodicos.cfs.ifmt.edu.br/periodicos/index.php/rpd/article/view/550/265. Acesso em: 30 ago. 2020.

SILVA, João Batista da; SALES, Gilvandenys Leite; CASTRO, Juscileide Braga de; Gamificação como estratégia de aprendizagem ativa no ensino de Física. Revista Brasileira de Ensino de Física, v. 41, n. 4, p. 2-8, 2019. Disponível em:

https://www.scielo.br/pdf/rbef/v41n4/1806-9126-RBEF-41-4-e20180309.pdf. Acesso em 07 de out. de 2020.

SOARES, Marlon Hebert Flora Barbosa. Jogos e Atividades lúdicas Para o Ensino da Química. Goiânia: Kelps, 2015.

SOUZA, Valeska Virgínia Soares; REIS, Isadora Aparecida Ribeiro dos; OLIVEIRA, Sabrina Aryane de Souza. Playing trace effects with brazilian high school students: complexity and games. Revista Desempenho, v. 1, n. 23, p. 1-21, 3 out 2015. Disponível em: https://periodicos.unb.br/index.php/rd/article/view/9473/8371. Acesso em: 30 ago. 2020.

TEIXEIRA, Ricardo Roberto Plaza; APRESENTAÇÃO, Kátia Regina dos Santos. Jogos em sala de aula e seus benefícios para a aprendizagem da matemática. Revista Linhas, v.15 n. 28, p. 302-323, 2014. Disponível em: http://www.revistas.udesc.br/index.php/linhas/article/view/1984723815282014302/3103. Acesso em: 30 ago. 2020.

VYGOTSKY, Levy. O papel do brinquedo no desenvolvimento. In: VYGOTSKY, Levy. A formação social da mente. São Paulo: Martins Fontes, 1989. p. 105-118.

Recebido em: 1 de setembro de 2020.

Aprovado em: 14 de outubro de 2020. 